\title{
Review on Natural Dye-Sensitized Solar Cells (DSSCs)
}

\author{
Oluwaseun Adedokun ${ }^{\ddagger}$ Kamil Titilope, Ayodeji Oladiran Awodugba \\ Department of Pure and Applied Physics, Ladoke Akintola University of Technology, P.M.B. 4000, Ogbomoso, Nigeria \\ (oadedokun@lautech.edu.ng, katitilope@student.lautech.edu.ng, aoawodugba@lautech.edu.ng) \\ "Corresponding Author: Oluwaseun Adedokun, Department of Pure and Applied Physics, Ladoke Akintola University of \\ Technology, P.M.B. 4000, Ogbomoso, Nigeria, Tel: +2347031195750, oadedokun@lautech.edu.ng
}

Received: 22.03.2016 Accepted: 25.04.2016

\begin{abstract}
In a conversion system of pure and non-convectional solar energy to electricity, dye sensitized solar cells (DSSCs) encourage the fabrication of photovoltaic devices providing high conversion efficiency at low cost. The dye as a sensitizer plays a vital role in performance evaluation of DSSCs. Natural dyes (organic dyes) has come to be a worth-while substitute to the rare and expensive inorganic sensitizers because of its cost effective, extreme availability and biodegradable. Different parts of a plant like fruits, leaves, flowers petals and bark have been tested over the years as sensitizers. The properties, together with some other parameters of these pigments give rise to improve in the operation standard of DSSCs. This review hash-out the history of DSSC with a focus on the recent developments of the natural dyes applications in this specific area with their overall appearance, the various components and the working principle of DSSCs as well as the work done over the years on natural dye based DSSCs.
\end{abstract}

Keywords: Natural dye, DSSCs, photovoltaic device, Photo-electrode, photo-sensitizer.

\section{Introduction}

Solar energy provides a clean, renewable and cheaper energy source for human race, while serving as a primary energy source for another type of energy sources, namely; wind energy, water, bio-energy and fossil fuel. The solar cells used in harvesting the solar power are commonly categorized into different types in respect to the composition of their material e.g organic dye solar cells, non-crystal, multiple crystal, and single crystal silicon solar cells. A solar cell usually signifies the cell that is made from silicon crystal material. Nevertheless, the production cost of the solar cells based on silicon crystal material compared to the dyesensitized solar cells (DSSCs) is high. DSSCs have triggered a great attention and they are of powerful interest due to the advantages of its lower cost of manufacturing.

DSSCs are devices that convert solar to electric energy by light sensitization established on wide energy band semiconductor [1]. DSSC shows a very promising future in the field of photovoltaic cells $[2,3]$. DSSC also known as Grätzel cell is a new type of solar cell [4], and have attracted a great interest due to their minimal production cost, and environmental friendliness. DSSC comprises of a counter electrode, an electrolyte containing iodide and triiodide ions, and a nano-crystalline porous semiconductor electrodeabsorbed dye. The dye which acts as sensitizers in DSSCs plays an important task in absorption and conversion of incident light ray to electricity.

Dyes are classified into organic (natural dye) and inorganic dye. Inorganic dyes such as Ruthenium (Ru) dyes are presently known to be the most significant dye for the fabrication of DSSCs with great efficiency. However, they are quite expensive and difficult in their purification. Therefore, in finding alternative to the expensive and rare inorganic sensitizers, natural dyes are considered as the best viable alternative. The main advantages of using natural pigment as sensitizer in DSSCs are low fabrication cost, easy achievability, low time of energy payback, flexibility, availability supply of raw materials, non-environmental risk, and great performance at diffuse light and multicolor options. Different parts of plant e.g leaves, flowers petal and barks have been examined as sensitizers [5]. The nature and some other parameters of these pigments gave rise to varying performance in their efficiency [5].

The operations of DSSCs are based on the photosensitization created by the dyes on wide band-gap mesoporous metal oxide semiconductors; this sensitization is 
due to the dye absorption of part of the visible light spectrum $[6,7]$. The use of natural pigments as sensitizing dye for the transformation of solar to electric energy is remarkable because, it enhances the economical aspect and in addition, it has important advantages from the environmental perspective $[8,9]$. DSSCs became more interesting since large collections of dye including natural dye can be used as light harvesting elements to provide the charge carriers. This review hash-out the history of DSSC with a focus on the recent developments of the natural dyes applications in this specific area with their overall appearance, the various components and the working principle of DSSCs as well as the work done over the years on natural dye based DSSCs.

\section{Structure and Operation of DSSCs}

\subsection{Structure of DSSC}

DSSC differs from other solar cell devices both by its basic construction and the physical processes behind its operation. In contrast to the first and second generation, PV devices based on solid-state semiconductor materials, the typical DSSC arrangement combines liquid and solid phases. DSSC comprises of a transparent conducting glass electrode (anode) that allows the passage light through the cell [11, 12]. Transparent glasses are used as electrode substrates due of their availability, affordable cost, and great transparency in the visible spectrum. The fluorine tin dioxide $\mathrm{F}: \mathrm{SnO}_{2}$ coating has a transparent conductive face. The mesh titanium nanoparticle $\mathrm{TiO}_{2}$ acts as a dye container, and provides electron passage through the cell. The $\mathrm{TiO}_{2}$ particles are coated with dye molecules (light sensitizer) that convert photons into excited electrons and cause current to flow. The dye is surrounded by the electrolyte layer (usually iodide) that acts as a source to compensate the lost electron. The counter electrodes (cathode) on the other side of the cell are typically coated with platinum or graphite.

\subsection{Operation of DSSCs}

Operation in DSSC is similar to photosynthesis with dye replacing chlorophyll as light harvesting element for the production of excited electrons, carbon dioxide being replaced $\mathrm{TiO}_{2}$ as the electron acceptor; oxygen as the electron donor and oxidation product; electrolyte substitutes water; and a multilayer structure to improve both absorption of light and efficiency in collection of electron. The light driven electro-chemical process in DSSC is regenerative as shown in Figure 1 and the working voltage produced by the device is the difference between the chemical potential of the $\mathrm{TiO}_{2}$ (Fermi level) and the redox potential of the mediator [13]. The transferred of electron to the electrolyte is made at the cathode. The electrolytes containing $\mathrm{I}^{-} / \mathrm{I}_{3}^{-}$are used as brokers between the cathode (carbon plated counter electrode) and the $\mathrm{TiO}_{2}$ photo electrode. Thus, the oxidized dye receives electron from $\mathrm{I}^{-}$ion redox to replace the lost electron [14-16], and the iodide molecules are then oxidized into tri-iodide ions $\left(\mathrm{I}_{3}^{-}\right)$. This process is described by Equation 4. Hence, the DSSCs efficiency sensitized by Ru compound, adsorbed on the semiconductor nano-crystalline $\mathrm{TiO}_{2}$ has reached $11-12 \%[17,18]$.

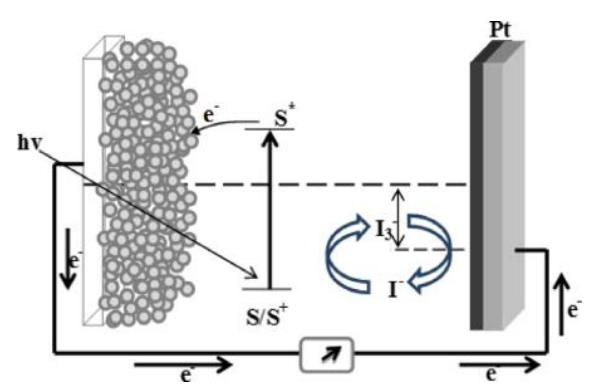

Fig. 1. A Schematic diagram and operational principle of DSSC [10]

The operation cycle is summarized in chemical reaction as [19]:

Anode:

$\mathrm{S}+\mathrm{hv} \rightarrow \mathrm{S} *$

$\mathrm{S} * \rightarrow \mathrm{S}^{+}+\left(\mathrm{TiO}_{2}\right) \quad$ Electron injection

$2 \mathrm{~S}^{+}+3 \mathrm{I}^{-} \rightarrow 2 \mathrm{~S}+\mathrm{I}^{3} \quad$ Regeneration

Cathode:

$\mathrm{I}_{3}^{-}-2 \mathrm{e}^{-}(\mathrm{Pt}) \rightarrow 3 \mathrm{I}^{-}$

Cells:

$\mathrm{e}^{-}(\mathrm{Pt})+\mathrm{hv} \rightarrow 3 \mathrm{I}^{-}$

where $\mathrm{S}$ is the dye molecule and $\mathrm{hv}$ is the photon energy.

There are no consumption or production of any chemical substances during the operational cycle, thus the operation of the cell is regenerative in nature, as shown in Equation 5.

\section{Components of DSSCs}

The conversion of light energy in-to electricity done by DSSC is based on sensitization of wide band gap semiconductors and mainly consists of dye, photo electrode, electrolyte, counter electrodes and substrates glass with the transparent conductive oxide (TCO) layer. The optimization of each of them is highly significant to improve the overall efficiency.

\subsection{Photosensitizer}

An efficient photosensitizer has several basic fabrication requirements including:

- Strong dye adsorption particles onto the semiconductor surface;

- Large visible light harvesting capacity;

- Injection of electron efficiently into the semiconductors conduction band;

- Lastly, $-\mathrm{O}$ or $-\mathrm{OH}$ groups with anchoring capability on $\mathrm{TiO}_{2}$ surface, ensuring high rates in transfer of electron.

Dye has essential roles in absorbing and converting solar to electric energy. Numerous researches focused on molecular engineering of several inorganic metal complexes and organic dyes. Transition coordination complexes are used as charge transfer sensitizers, harvesting around $11 \%$ solar to electric energy in standard global air mass AM 1.5 of sunlight [20]. These complexes are also one of the most effective sensitizers because of their greater efficiency, chemical stability, favorable photo-electrochemical properties etc. $[21,22]$. Nonetheless, $\mathrm{Ru}$ complexes contained heavy metals which are hazardous 
environmentally, aside from their complicated and expensive synthesis. Moreover, $\mathrm{Ru}$ complexes have the tendency to degrade in the presence of water [4, 23-24].

Grätzel and his group developed many Ru complex photosensitizers [22] which represent the most efficient sensitizers $(-11 \%)$ because of their intense range of absorption from the visible to the near-infrared region [25, 26]. Regardless of their chemical stability and the possible exchange of charging with semiconducting solids, Ru complexes have large visible light-harvesting capacity which makes them a wise choice for the manufacture of solar energy conversion devices $[27,28]$.

\subsection{Electrolytes}

The electrolyte plays a very essential role in the DSSC by enabling the transport of charge between the photo-electrode and counter electrode. The ideal electrolyte solvent is one that has small vapor pressure, very low viscosity, high dielectric properties and high boiling point. From industrial point view, factor like easy processing, robustness (chemical inertness), and environmental sustainability are also important. Presently, the most successful redox mediator used in DSSC includes a liquid electrolyte containing the redox couple iodide/triiodide. The redox electrolyte comprises of iodine, iodides and often additional additives. Ionic liquids are promising alternative electrolytes which provide advantages like high thermal and chemical stability, non-volatility, and excellent ionic conductivity. Finding a superior redox couple is one of the main challenges for future DSSCs research.

\subsection{Conductive Glass or Substrates}

Clear conductive glasses are usually employed as substrate due to their relatively minimal cost, abundant in supply, high optical. Conductive coating is made by deposition of one side of the substrate in form of thin transparent conductive oxide (TCO). This layer is crucial because it enables the penetration of sunlight into the cell while conducting electron carriers to outer circuit. The conductive film ascertain a very low electrical resistance of about $10-20 \Omega$ per square at room temperature. The nanostructure wide band gap oxide semiconductor (electron acceptor) is applied on the conductive side.

\subsection{Photo-Electrode}

The photo-electrode in a DSSC comprises of a nanostructure semiconductor materials, clipped to a transparent conducting substrate. The most widely used semiconductor material is $\mathrm{TiO}_{2}$ because $\mathrm{TiO}_{2}$ is an inexpensive, nontoxic and abundant material. The electrode comprises of interconnected nanoparticles, with size ranging between 15-30 $\mathrm{nm}$. They appear as a transparent porous electrode, with an average thickness of 10-15 $\mu \mathrm{m}$. The deposition techniques mainly employed for the film preparation are screen printing and doctor blading. Both methods involve the deposition of viscous colloidal $\mathrm{TiO}_{2}$ onto a substrate before sintering process. Sintering is commonly carried out at temperatures of $450-500{ }^{\circ} \mathrm{C}$. The high temperature results in electrical interconnection among the nanoparticles, and eventually forms the nanostructure porous electrode. The sensitization of dye is performed by dipping the electrode into a dye solution for some time.

\subsection{Counter Electrode}

The counter electrode is an essential component in DSSC where the reduction of mediator takes place. It comprises of fluorine-doped tin oxide (FTO), glass coated with platinum to ensure more reversible transfer of electron. The counter electrode enables electrons transfer coming from the external circuit back to the redox electrolyte. Furthermore, it serves to carry the photo-current over the width of each solar cell. Therefore, the counter electrode must be conducting efficiently and show a low over-voltage for redox couple reduction. Until now, platinum $(\mathrm{Pt})$ has been the desired material for the counter electrode because of its excellent performance in reduction of $\mathrm{I}_{3}^{-}$[29].

\section{Reviews of Dyes Used in DSSCs}

The dyes applied in DSSCs are categorized into two types which are organic and inorganic dyes. Inorganic dyes comprises of metal complex, e.g polypyridyl complexes of Ruthenium and Osmium, metal porphyrin, phthalocyanine and inorganic quantum dots, while organic dye comprises of natural and synthetic dyes.

\subsection{Natural Dye Sensitizers}

Another type of dye sensitizers used is the organic or natural dye. Natural dyes offers a suitable alternative to high cost inorganic based DSSCs. Naturally, the fruits, flowers and leafs of plant shows different colors from red to purple and include different natural dyes which can be extracted using simple procedure and used for DSSC fabrication [30]. Consideration have been made on natural pigments as a promising alternative sensitizer dyes for DSSC because of their simple production technique, affordable cost, complete biodegradation, easy availability, purity grade, environmental friendly, high reduction of noble metal, and chemical synthesis cost [31-33]. Plant pigmentation results from the electronic structure of pigments reacting with sunlight to change the wavelengths as may be perceived by the viewer. The pigment can be described by the maximum absorption wavelength $\left(\lambda_{\max }\right)$ [34]. The performance of natural dye sensitizer in DSSC has been estimated using fill factor (FF), energy conversion efficiency $(\eta)\left(J_{s c}\right)$, open circuit voltage $\left(\mathrm{V}_{\mathrm{oc}}\right)$, and short circuit current. Many parts of a plant have been tested by Researchers (see Table 1) and various useful dyes have been highlighted as photo-sensitizers for DSSC from natural products [35-42].

Common pigments are (a) Betalains (b) Carotenoids (c) Chlorophyll and (d) Flavonoids as Anthocyanins etc. Structures of some natural dyes employed in DSSCs are shown in Figure 2, 3 and 4.

\subsubsection{Flavonoids}

Flavonoids are widely distributed plant pigments. The word "flavonoid" is commonly employed to define a large group of natural products including C6 - C3 - C6 carbon structure or more specifically phenylbenzopyran functionality. 
INTERNATIONAL JOURNAL Of ENGINEERING TECHNOLOGIES

Oluwaseun Adedokun et al., Vol.2, No.2, 2016

Table 1. Photovoltaic parameters of natural dye based DSSCs

\begin{tabular}{|c|c|c|c|c|c|}
\hline Natural dyes & $\operatorname{Jsc}\left(\mathrm{mAcm}^{-2}\right)$ & $\operatorname{Voc}(\mathrm{V})$ & FF & Efficiency (\%) & References \\
\hline Bougainvillea & 2.10 & 0.30 & 0.57 & 0.36 & 35 \\
\hline Sicilian Indian & 2.70 & 0.38 & 0.54 & 0.50 & \\
\hline Perilla & 1.36 & 0.522 & 0.69 & 0.50 & 36 \\
\hline Tangerine peel & 0.74 & 0.592 & 0.63 & 0.28 & \\
\hline Petunia & 0.85 & 0.616 & 0.60 & 0.32 & \\
\hline Yellow rose & 0.74 & 0.609 & 0.57 & 0.26 & \\
\hline Violet & 1.02 & 0.498 & 0.64 & 0.33 & \\
\hline Begonia & 0.63 & 0.537 & 0.72 & 0.24 & \\
\hline Flowery knotweed & 0.60 & 0.554 & 0.62 & 0.21 & \\
\hline Lily & 0.51 & 0.498 & 0.67 & 0.17 & \\
\hline Fructus lycii & 0.53 & 0.689 & 0.46 & 0.17 & \\
\hline Mangosteen pericap & 2.69 & 0.686 & 0.63 & 1.17 & \\
\hline Bauhinia tree & 0.96 & 0.572 & 0.66 & 0.36 & \\
\hline Rhododendron & 1.61 & 0.585 & 0.61 & 0.57 & \\
\hline Chinese rose & 0.90 & 0.483 & 0.62 & 0.27 & \\
\hline Cofee & 0.85 & 0.559 & 0.68 & 0.33 & \\
\hline Marigold & 0.51 & 0.542 & 0.83 & 0.23 & \\
\hline Lithospermum & 0.14 & 0.337 & 0.58 & 0.03 & \\
\hline Rose & 0.97 & 0.595 & 0.66 & 0.38 & \\
\hline Mixed rosella blue pea & 0.82 & 0.38 & 0.47 & 0.15 & 37 \\
\hline Kelp & 0.43 & 0.44 & 0.62 & & 38 \\
\hline Capsicum & 0.23 & 0.41 & 0.63 & & \\
\hline Black rice & 1.14 & 0.55 & 0.52 & & \\
\hline Rosa xanthina & 0.64 & 0.49 & 0.52 & & \\
\hline Erythrina variegate & 0.78 & 0.48 & 0.55 & & \\
\hline Annatto & 0.53 & 0.56 & 0.66 & 0.19 & 39 \\
\hline Bixin & 1.10 & 0.57 & 0.59 & 0.37 & \\
\hline Norbixin & 0.38 & 0.53 & 0.64 & 0.13 & \\
\hline Crocin & 0.45 & 0.58 & 0.60 & 0.16 & 40 \\
\hline Crocetin & 2.84 & 0.43 & 0.46 & 0.56 & \\
\hline Syrup of Calafate & 1.50 & 0.38 & 0.2 & & 41 \\
\hline Fruit of Calafate & 6.20 & 0.47 & 0.36 & & \\
\hline Skin of Jaboticaba & 7.20 & 0.59 & 0.54 & & \\
\hline Nerium olender & 2.46 & 0.41 & 0.59 & 0.59 & 42 \\
\hline Hibiscus rosasinesis & 4.04 & 0.40 & 0.63 & 1.02 & \\
\hline Hibiscus surattensis & 5.45 & 0.39 & 0.54 & 1.14 & \\
\hline Ixora macrothyrsa & 1.31 & 0.40 & 0.57 & 0.30 & \\
\hline Sesbania grandiflora & 4.40 & 0.41 & 0.57 & 1.02 & \\
\hline
\end{tabular}


Over 5000 naturally occurring flavonoids have been extracted from various plants, and divided according to their chemical structure as follows: flavonols, flavones, flavanones, isoflavones, catechins, anthocyanin, and chalcones. There are three classes of flavonols which are: flavonoids (2-phenylbenzopyrans), isoflavonoids (3benzopyrans), and neoflavanoids (4-bezopyrans). Flavonoids contain 15-carbon (C15) based structure with two phenylrings joined by three carbon bridges, forming a third ring. The phenyl ring oxidation degree (C-ring) identifies the different colors of flavonoids. However, not all flavonoids have the capability of absorbing visible light, although they have similar structures. Flavonoid molecules are characterized by loose electrons; thus, the energy required for electron excitation to LUMO is lowered, allowing visible light to energize the pigment molecules. Flavonoids regularly occur in fruits, where animals that feed and diffuse the seeds of fruits are attracted, as well as in flowers where insect pollinators are attracted. Many flavones and flavonols absorb radiations most concentrated in ultraviolet (UV) region forming special UV patterns on flowers which are visible to bees. They are also present in the leaves of many species, where they protect plants by screening out harmful ultraviolet radiation from the Sun. Flavonols, Anthocyanins, and proanthocyanidins are three major subcategories of flavonoid compounds.

\subsubsection{Carotenoids}

Carotenoids are organic pigments found in both chloroplasts and chromoplasts of plants and some other photosynthetic organisms, including some fungi and bacteria. Carotenoids play two important roles in plants and algae: absorption of light energy for use in photosynthesis, and protection of chlorophyll from photo-damage [43]. Carotenoid pigments do make provisions for many flowers and fruits with typically red, yellow and orange colors, and numbers of carotenoid derived aromas. There are over 600 carotenoids known and are divided into two categories; carotenes (pure hydrocarbons) and xanthophylls (which contain oxygen). All carotenoids are tetraterpenoids, meaning that they are produced from 8 isoprene molecules and contain 40 carbon atoms. Generally, carotenoids absorb wavelengths ranging from 400-550 nanometers (violet to green light).

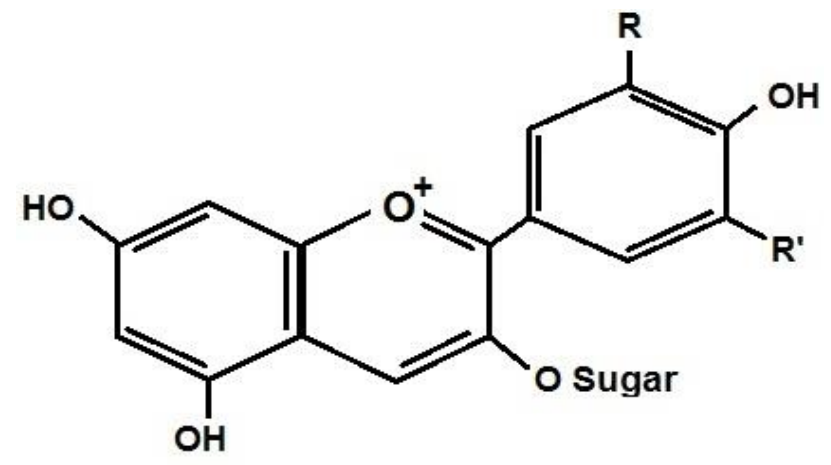

Anthocyanin

Fig. 2. Structure of Flavonoid (Anthocyanin)
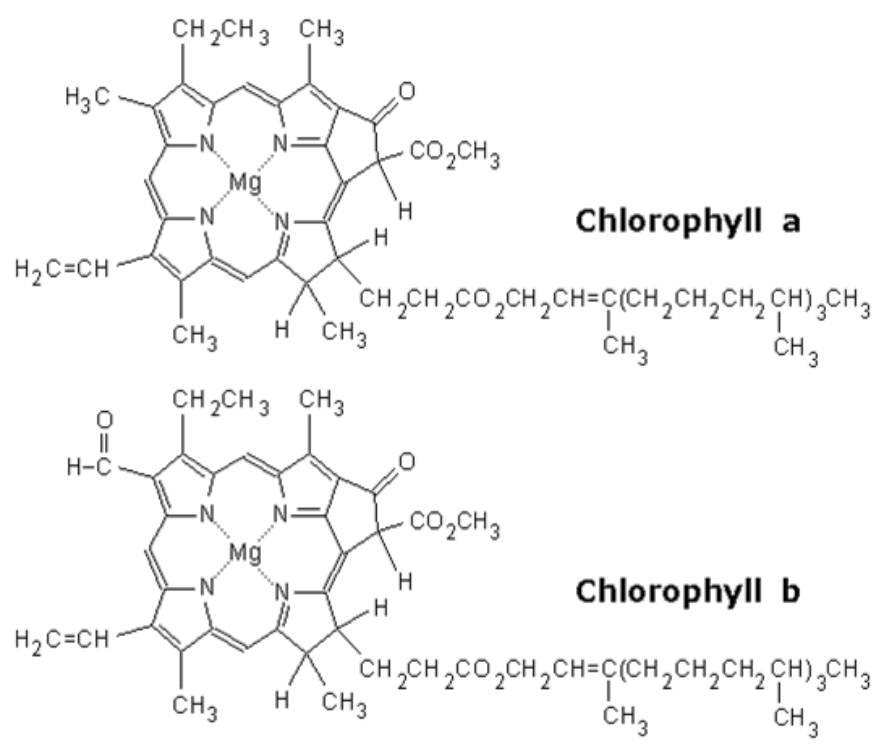

Fig. 3. Structure of Chlorophyll a and b

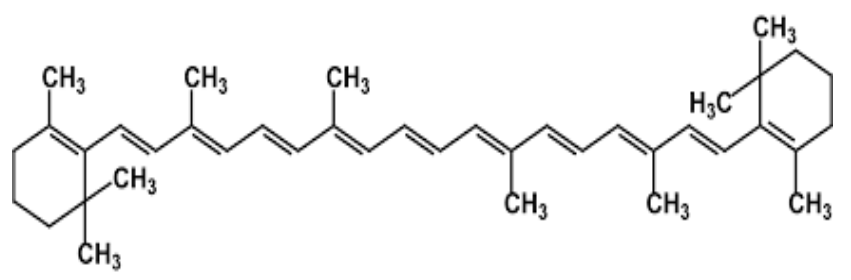

Fig. 4. Structure of carotenoids

\subsubsection{Chlorophyll}

Chlorophyll $(\mathrm{Chl})$ is a green pigment found in the leaves of most green plants, cyanobacteria, and algae. There are six types of chlorophyll pigment, and the most occurring type is $\mathrm{Chl}$ a. Chlorophyll is a compound known as a chelate which is composed of hydrogen, carbon, a central metal ion joined to a large organic molecule, and some other elements like oxygen and nitrogen. In photosynthesis, absorption of energy is done by chlorophyll for the transformation of carbon dioxide to carbohydrates and water to oxygen. This process converts solar energy to a form that can be utilized by plants. The molecular structure contains chlorine ring with $\mathrm{Mg}$ center, together with various side chains and a hydrocarbon trail, depending on the Chl type (Fig. 3). Chls are the most important pigments in natural photosynthetic systems [44, 45]. Their functions consist harvesting sunlight, converting solar to chemical energy, and electrons transfer. Chls include a group of more than 50 tetrapyrrolic pigments [46]. Chls and their derivatives are inserted into DSSC as dye sensitizers because of their beneficial light absorption tendency modes; the most efficient of which is Chl $\alpha$ (chlorine 2) derivative-methyl trans- $3^{2}$-carboxypyropheophorbide $\alpha$. Xiao et al., reported that chlorine 2 has an ability to lead 4semiconductors $\mathrm{TiO}_{2}$ and $\mathrm{ZnO}$ surfaces through different modes [47]. Maximum absorption is achieved by Chlorophyll at $670 \mathrm{~nm}$ because of an interesting compound that acts as a photosensitizer in the visible light range.

Chlorophyll-a is the primary pigment for photosynthesis in plants with the composition $\mathrm{C}_{55} \mathrm{H}_{72} \mathrm{O}_{5} \mathrm{~N}_{4} \mathrm{Mg}$ (Fig. 3). It 
exhibits a grass-green visual color and absorption peaks at $430 \mathrm{~nm}$ and $662 \mathrm{~nm}$.

Chlorophyll-b has the composition $\mathrm{C}_{55} \mathrm{H}_{70} \mathrm{O}_{6} \mathrm{~N}_{4} \mathrm{Mg}$, the difference from chlorophyll-a being the replacement of a methyl group with a CHO (Fig. 3). It exhibits a blue-green visual color and absorption peaks at $453 \mathrm{~nm}$ and $642 \mathrm{~nm}$.

\section{Performance Evaluation of DSSCs}

After the fabrication of a DSSC, it is now important to evaluate its performance. The two main criteria to consider are: Overall Energy Conversion Efficiency and the Photochemical stability. Other required parameters are IPCE (Incident Photon to Current Efficiency also known as Quantum efficiency), $\mathrm{I}_{\mathrm{sc}}$ (short-circuit-current), $\mathrm{V}_{\mathrm{oc}}$ (opencircuit-voltage), FF (fill-factor). The short circuit-current is the current across the solar cell when the voltage passing through the solar cell is zero (i.e., when the solar cell is short circuited). Open Voltage Current is the maximum voltage available from a solar cell and this occurs at zero current. Fill factor is described as the rate of the maximum power from the actual solar cell per maximum power from an ideal solar cell. Efficiency is described as the ratio of energy output from the solar cell to input energy from the sun. Any photovoltaic device should have a serviceable life of about 20 years without significant loss of performance. Efficient dyes like N3 sustained 108 cycles after long time illumination. Regeneration is an important factor here, and it should occur fast to maintain the long term stability of the cell. Common tests are based on $1000 \mathrm{~h}$ stability tests at $80 \mathrm{oC}$ for evaluating the photochemical stability of the DSSC.

The absorption spectra of dye solutions and dyes adsorbed on $\mathrm{TiO}_{2}$ surface were recorded using a VIS Spectrophotometer (Spectrum lab 23A GHM Great Medical England).

The fill factor $(\mathrm{FF})$ is defined as:

$\mathrm{FF}=\frac{\left(\mathrm{I}_{\max } \times \mathrm{V}_{\max }\right)}{\left(\mathrm{I}_{\mathrm{sc}} \times \mathrm{V}_{\mathrm{oc}}\right)}$

where $\mathrm{I}_{\max }$ is photo-current and $\mathrm{V}_{\max }$ is photovoltage.

$I_{s c}$ is short-circuit photo-current and $V_{o c}$ open-circuit photovoltage, respectively.

Energy conversion efficiency $(\eta)$ is defined as:

$\eta=\frac{\left(\mathrm{I}_{\mathrm{sc}} \times \mathrm{V}_{\mathrm{oc}} \times \mathrm{FF}\right)}{\mathrm{P}_{\mathrm{in}}}$

where, $\mathrm{P}_{\text {in }}$ is incident light power.

\section{Challenges}

Despite the fact that the cost DSSCs compared to the silicon solar cells is predicted to be at least five times lower which then encourage the use of DSSCs, they also have their limitations regardless of their low cost and easy procedure in fabrication. The main limitation of DSSCs can be recapped as low scalability, low efficiency, and low stability. The efficiency depends on many factors, like $\mathrm{V}_{\mathrm{oc}}$ (open circuit voltage), $\mathrm{I}_{\mathrm{sc}}$ (short circuit current), internal resistances and FF (fill factor). DSSCs make use of an organic dye to absorb incidence light ray to give off excited electrons and produce an energy which is then transferred to a material, like titanium dioxide $\left(\mathrm{TiO}_{2}\right)$. The energy is therefore collected through a transparent conducting medium. This task presents experimental challenges due to the various basic components found in these cells and their several likely combinations. The obtained photo-conversion efficiencies till date are still low, despite the substantial experimental struggle on their enhancement. At present, its conversion efficiency ranges between $8 \%$ and $11 \%$ which is below the standard of most current solar technology. The conversion efficiency could be improved through the reduction of some internal resistances. Several ways for the reduction of the cell internal resistances are: adjusting the thickness of the electrode conducting layer, adjust the roughness factor and minimizing the gaps between electrodes. Stability study shows that DSSCs are not yet reliable to predict their efficiency and performance for a long time. The DSSC system in respect to the sealing procedure and material needs to be further studied.

\section{Conclusions}

Ruthenium $(\mathrm{Ru})$ dyes as part of the inorganic dyes are presently taken as the best dye for the fabrication of efficient DSSC having efficiency of $10-11 \%$. Meanwhile, the noble metal Ruthenium is not abundant and very expensive. Therefore, to achieve a cheaper dyes for DSSC, the use of natural dyes (organic dye) extracted from different easily available fruits and flowers as sensitizers in DSSCs are the suitable alternative for possible application as sensitizers to inorganic dyes because of their low cost, metal-free, ecofriendliness, availability, simple preparation technique and wide availability. Recent developments on different kinds of sensitizers for DSSC devices have led to the use of natural dyes that absorb sunlight within the visible spectrum with higher efficiencies. The nature of the dye used as sensitizers is the main factor affecting the DSSC efficiency. The betalain pigment in red turnip extract recorded the highest efficiency of $1.70 \%$. Although the results obtained on the efficiencies of DSSC with natural dyes are lower than the expectations required for large-scale fabrication, the efficiency are still encouraging and can enhance further researches on the study of new natural sensitizers and to improve the standard of compatible solar cell components for such dyes. This study encourages further research on the use of new natural dye sensitizers to increase the efficiency and stability of DSSC for future satisfactory photoelectric conversion efficiency. Moreover, the new sensitizers should have the following characteristics:

- Higher redox cycles without undergoing decomposition;

- Ability to carry attachment groups, such as phosphonate or carboxylate, to absorb $\mathrm{TiO}_{2}$; and

- Capability to take-in all the sunlight under the threshold wavelength of $920 \mathrm{~nm}$.

\section{Acknowledgement}

One of the authors is grateful to TWAS for 2013 TWASCSIR Postgraduate fellowship. 


\section{References}

[1] M. Gratzel, (2003) Dye-sensitized solar cells, J. Photochem. Photobiol. C, 4: 145-153.

[2] B. O’Regan, M. Gratzel, (1991) A Low-cost highefficiency solar cell based on dye-sensitized colloidal $\mathrm{TiO} 2$ films, Nature, 353: 737-740.

[3] J. O. Ozuomba, A. J. Ekpunobi, P. I. Ekwo, (2011) The viability of prophyrin local dye in the fabrication of dyesensitized solar cells, Digest J. Nanomaterials and Biostructures, 6(3): 1043 - 1051.

[4] M. Gratzel, (1991) Review article photo-electrochemical Cells, Nature 414, 338-344.

[5] M.R. Narayan, (2012) Review: Dye sensitized Solar Cells based on natural photosensitizers, Renewable and Sustainable Energy Reviews 16:208-215.

[6] M. Grätzel, (2005) Solar Energy Conversion by DyeSensitized Photovoltaic Cells, Inorg. Chem. 44: 6841-6851.

[7] N.M. Gómez-Ortíz, I.A. Vázquez-Maldonado, A.R. Pérez-Espadas, G.J. Mena-Rejón, J.A. Azamar-Barrios, G. Oskam, (2009) Dye-sensitized solar cells with natural dyes extracted from a chiote seeds. Sol. Energy Mater. Sol. Cells, 94: 40-44.

[8] A. Kay and M. Gratzel, (1993) Natural Pigment-Based Dye-Sensitized Solar Cells, J. Phys. Chem., 97 (23): 6272 6277.

[9] M. K. Nazeeruddin, A. Kay, I. Rodicio, (1993) Conversion of light to electricity by cis-X2bis(2,2'-bipyridyl4,4'-dicarboxylate) ruthenium(II) charge-transfer sensitizers (X = Cl-, Br-, I-, CN-, and SCN-) on nanocrystalline titanium dioxide electrodes, J. Amer. Chem. Soc., 115 (14): 63826390 .

[10] I. Jinchu, C.O Sreekala, K.S. Sreelatha, (2014) Dye sensitized solar cells using Natural dyes as chromophores Review, Material Science Forum 741: 39-51.

[11] C. Bauer, G. Boschloo, E. Mukhtar, A. Hagfeldt, (2002) Interfacial electron-transfer dynamics in Ru(tcterpy)(NCS)3sensitized $\mathrm{TiO}_{2}$ nanocrystalline solar cells. J PhysChem B, 106:12693-704.

[12] L. Antonio, S. Hegedus, (2003) Handbook of photovoltaic science and engineering. 1st ed.. UK: John Wiley \& Sons Ltd Publishers

[13] N.J. Cherepy, G.P. Smestad, M. Grätzel, J.Z. Zhang, (1997) Ultrafast electron injection: implications for a photoelectrochemical cell utilizing an anthocyanin dye-sensitized $\mathrm{TiO}_{2}$ nano-crystalline electrode. Journal of Physical Chemistry; 101: 9342-51.

[14] G.P. Smestad, (1998) Education and solar conversion: demonstrating electron transfer, Sol Energy Mater Sol Cells; 55:157-78.
[15] G. Calogero, G.D. Marco, (2008) Red Sicilian orange and purple eggplant fruite as natural sensitizers for dyesensitized solar cells, Sol Energy Mater Sol Cells; 92:13416.

[16] C. Bauer, G. Boschloo, E. Mukhtar, A. Hagfeldt (2002) Ultrafast studies of electron injection in $\mathrm{Ru}$ dye sensitized $\mathrm{SnO}_{2}$ nanocrystalline thin film, Int. J Photo- energy; 4:17-20.

[17] Y. Chiba, A. Islam, Y. Watanabe, R. Komiya, N. Koide, L.Y. Han, (2006) Dye sensitized solar cells with conversion efficiency of 11.1\%. Jpn J Appl Phys, 45: L638L640.

[18] R. Buscaino, C. Baiocchi, C. Barolo, C. Medana, M. Gratzel, M.D.K. Nazeeruddin, (2008) A mass spectrometric analysis of sensitizer solution used for dye sensitized solar cell. Inorg Chim Acta, 361:798-805.

[19] D. Matthews, P. Infelta, M. Grätzel, (1996) Calculation of the photocurrent-potential characteristic for regenerative, sensitized semiconductor electrodes. Solar Energy Materials and Solar Cells, 44:119-55.

[20] N.A. Ludin, A.M. Al-Alwani Mahmoud, A. Mohamad, A.H. Kadhum, K. Sopian, N. S. Abdul Karim, (2014) Review on the development of natural dye photosensitizer for dye-sensitized solar cells, Renewable and Sustainable Energy Reviews 31: 386-396.

[21] Hao S, Wu J, Huang Y, Lin J. (2006). Natural dyes as photosensitizers for dye-sensitized solar cell. Sol. Energy 80: 209-214.

[22] Hernandez-Martinez A.R., Estevez M, Vargas S, Quintanilla F, Radriguez R. (2012) Natural pigment based dye-sensitized solar cells. J Appl Res Technol., 10: 38-47.

[23] Zhang D, Lanier S.M., Downing J.A., Avent J.L., Lum J., Mc Hale J.L. (2008) Betalain pigments for dye-sensitized solar cells. J Photo chem Photo bio 1 A: Chem, 195:72-80.

[24] P.S. Greg, M. Grätzel (1998) Demonstrating electron transfer and nanotechnology: a natural dye sensitized nanocrystalline energy converter. J Chem Educ., 75:752-6.

[25] Monari A, Assfeld X, Beley M, Gros P.C. (2011) Theoretical study of new ruthenium based dyes for dyesensitized solar cells. J Phys Chem A, 115:3596-603.

[26] M.K. Nazeeruddin, P. Péchy, T. Renouard, (2001) Engineering of efficient panchromatic sensitizers for nanocrystalline $\mathrm{TiO}_{2}$ based solar cells. J Am Chem Soc., 123:1613-24.

[27] A.O. Adeloye, P.A. Ajibade, (2011) A high molar extinction coefficient mono- anthracenyl bipyridyl heteroleptic Ruthenium(II) complex: synthesis, photophysical and electrochemical properties. Molecules, 16:4615-31. 
[28] Yuancheng Q, Peng Q. (2012) Review articles: Ruthenium sensitizers and their application in dye sensitized solar cells. Int. J Photoenergy, 2012: 21 (Article ID291579).

[29] Luque A, Hegedus S. (2003) Handbook of photovoltaic science and engineering. The Netherlands: Elsevier.

[30] Chang H, Lo Y.J. (2010) Pomegranate leaves and mulberry fruit as natural sensitizers for dye sensitized solar cells. Sol Energy, 84:1833-7.

[31] Kishiomoto S, Maoka T, Sumitomo K, Ohmya A. (2005) Analysis of carotenoid composition in petals of calendula (Calendula of ficinalis L).Biosci Biotechnol Biochem., 69:2122-8.

[32] Keka S, Saha P.D., Datta S. (2012) Extraction of natural dye from etals Flam of forest (Buteamonosperma) flower: process optimization using response surface methodology (RSM). J Dyes Pigment, 94: 212-6.

[33] Nishantha M.R., Yapa YPYP, Perera VPS. (2012) Sensitization of photoelectrochemical solar cells with a natural dye extracted from Kopsia flavida fruit. Proceed Tech Sess., 28:54-8.

[34] Davies KM. (2004) Plant pigments and their manipulation, USA: Blackwell Publishing Ltd. Annual Plant Reviews; 342.

[35] Calogero G, Marco G.D., Cazzanti S., Caramori S., Argazzi R., Carlo A.D., (2010) Efficient dye-sensitized solar cells using red turnip and purple wild Sicilian prickly pear fruits. International Journal of Molecular Sciences 11: 254267.

[36] Zhou H., Wu L., Gao Y., Ma T. (2011) 'Dye-sensitized solar cells using 20 natural dyes as sensitizers'. J. Photochem. Photobiol. A: Chem. 219: 188-194.

[37] Wongcharee K., Meeyoo V., Chavadej S. (2007) Dyesensitized solar cell using natural dyes extracted from rosella and blue pea flowers. Sol. Energy Mater. Sol. Cells, 91: 566571 .

[38] Hao S, Wu J, Huang Y, Lin J. (2006) Natural dyes as photosensitizers for dye-sensitized solar cell. Sol. Energy 80: 209-214.
[39] Gòmez-Ortíz N.M., Vázquez-Maldonado I.A., PérezEspadas A.R., Mena-Rejón G.J., Azamar-Barrios J.A., Oskam G. (2009) Dye-sensitized solar cells with natural dyes extracted from achiote seeds. Sol. Energy Mater. Sol. Cells, 94: 40-44.

[40] Yamazaki E, Murayama M, Nishikawa N, Hashimoto N, Shoyama M, Kurita O. (2007) Utilization ofnatural carotenoids as photosensitizers for dye-sensitized solar cells. Sol. Energy 81: 512-516.

[41] Polo AS, Iha NYM. (2006) Blue sensitizers for solar cells: natural dyes from Calafate and Jaboticaba. Sol. Energy Mater. Sol. Cells, 90: 1936-1944.

[42] Hernández-Martínez AR, Vargas S, Estevez M, Rodríguez R. (2010) Dye-sensitized solar cells from extracted bracts bougainvillea betalain pigments. In: 1st International Congress on Instrumentation and Applied Sciences, 1-15.

[43] G.A. Armstrong, J.E. Hearst (1996) Carotenoids 2: Genetics and molecular biology of carotenoid pigment biosynthesis. FASEB J. 10 (2): 228-37. PMID 8641556.

[44] X.F. Wang, J. Xiang, P. Wang, Y. Koyama (2005) Dye sensitized solar cells using chlorophyll a derivate as the sensitizer and carotenoids having different conjugation lengths as redox spacers. Chem Phys Lett., 408: 409-14.

[45] H. Chang, M.J. Kao, T.L. Chen, H.G. Kuo, K.C. Choand, X.-P. Lin, (2011) Natural sensitizer for dyesensitized solar cells using three layers of photoelectrode thin films with a Schottky barrier. Am J Eng Appl Sci., 4: 214 22.

[46] H.I. Scheer In: B.R. Green, W.W. Parson, Editors. (2003) Light-harvesting antennas in photosynthesis. Dordrecht: Kluwer Academic Publishers; p. 513.

[47] X.F. Wang, K. Osomu, H. Eiji, Z. Haoshen, S. Shin ichi, T. Hitoshi, (2010). $\mathrm{TiO}_{2}$ and $\mathrm{ZnO}$ based solar cells using a chlorophyll a derivative sensitizer for light-harvesting and energy conversion. J Photochem Photobiol A: Chem, 210: $145-52$. 